\title{
Aftercare for the prevention of a secondary health disaster in survivors of major earthquakes
}

\author{
Kenichi Tanaka, Masaaki Nakayama, Makoto Kanno, Hiroshi Kimura, Kimio Watanabe, Yoshimitsu Hayashi, \\ Koichi Asahi and Tsuyoshi Watanabe
}

Hypertension Research (2013) 36, 759-761; doi:10.1038/hr.2013.75; published online 11 July 2013

$\mathrm{O}$ 11 March 2011, Japan suffered a massive magnitude 9.0 earthquake. The resulting damage was extensive, particularly due to the tsunami that hit immediately after the earthquake, destroying or carrying away everything in its path and leaving 18574 people either missing or dead.

It has long been known that the health of major earthquake and other natural disasterrelated victims may suffer as a result of psychological stress and changes in their environment, and previous studies have found such victims to be associated with increased mortality from cardiovascular diseases such as acute coronary syndrome, stroke and pulmonary embolism. ${ }^{1,2}$ These deaths are recognized as so-called 'disasterrelated deaths,' and, in addition to emergency treatment immediately after a disaster, it is important to minimize such deaths in disaster medicine from the acute to the chronic phase. Detailed studies of postearthquake health problems following the Great Hanshin-Awaji Earthquake that struck Japan in 1995 found that the total number of acute myocardial infarctions in the earthquake-affected area during the 4-week period after the quake was $\sim 3.5$-fold greater than the total number from the previous year. ${ }^{3}$ In terms of the underlying mechanism, the psychological stress associated with the severe terror experienced at the time of the earthquake is thought to have had a major impact in activating the sympathetic nervous

K Tanaka, M Nakayama, M Kanno, H Kimura, K Watanabe, Y Hayashi, K Asahi and T Watanabe are at the Department of Nephrology and Hypertension, Fukushima Medical University, Fukushima, Japan and K Tanaka and K Asahi are at the Department of Chronic Kidney Disease Initiatives, Fukushima Medical University, Fukushima, Japan

E-mail: kennichi@fmu.ac.jp system, the hypothalamic-pituitary-adrenal axis and the renin-angiotensin system. This would have elevated the blood viscosity, impaired glucose metabolism and induced an inflammatory response, among other effects, and thus promoted cardiovascular events. 4

The contribution of elevated blood pressure is thought to be particularly significant, and the importance of blood pressure management in the aftermath of natural disasters to manage 'disaster hypertension' has been noted. ${ }^{5}$ Disaster-related deaths are particularly common among the elderly and patients with chronic conditions such as hypertension and diabetes; and as they increase in proportion to the damage situation, evacuation centers and other facilities must initiate continuous blood pressure management for high-risk patients beginning at an earlier stage in order to minimize both disaster-related deaths and post-disaster cardiovascular events.

Although the occurrence of post-earthquake cardiovascular events is evident beginning immediately after an earthquake, questions remain in relation to how long post-earthquake health damage continues in the form of disaster-related deaths and deteriorating blood pressure control as well as for how long careful health management of disaster victims is required. According to reports following the Great Hanshin-Awaji Earthquake, the increase in mortality resulting from cardiovascular events such as coronary artery disease continued for 'a few months' after the earthquake in the affected area. ${ }^{3,6}$ Blood pressure reportedly remained elevated for 4-6 weeks after the earthquake before returning to previous levels, ${ }^{7,8}$ indicating that a careful response to elevated blood pressure is required for at least 4 weeks after an earthquake.

A number of studies on disaster hypertension have also been performed since the Great East Japan Earthquake, all of which confirmed that blood pressure was significantly elevated in patients with hypertension, diabetes and chronic kidney disease for a period of a few weeks to a few months. ${ }^{9-12}$ The precipitous increase in blood pressure immediately after the earthquake was due to stress-induced rapid activation of the sympathetic nervous system, which was then prolonged by physical fatigue, chronic stress and lack of sleep owing to changes in the environment of the victims, and changes in lifestyle and dietary habits, particularly increases in salt intake from the food provided by evacuation centers and other facilities. However, observations were not continued for longer than a few months after the earthquake in any of those studies, and observations or investigations of additional long-term health problems among disaster victims have hardly been reported.

In a study published in this issue of Hypertension Research, Giorgini et al. ${ }^{13}$ investigated blood pressure changes in hypertensive patients $\sim 1$ year after the 2009 L'Aquila earthquake in Italy, with the aim of ascertaining the longer-term effects of health damage due to major earthquakes. The authors used 24-h ambulatory blood pressure monitoring records to evaluate the blood pressure management during the periods before $(6.9 \pm 4.5$ months) and after (14.2 \pm 5.1 months) the earthquake from 47 hypertensive patients with no history of diabetes, chronic kidney disease or heart failure. Patients were divided into the following three groups according to whether their antihypertensive drug regimen had been 
modified after the earthquake: unchanged therapy $(n=24)$; increased therapy $(n=17) ; \quad$ and reduced therapy $(n=6)$. Changes in blood pressure among the groups were then compared. The results showed that patients in the unchanged therapy group had markedly increased systolic and diastolic blood pressure, although $>1$ year had passed since the earthquake (24-h systolic blood pressure: $125.6 \pm 10.7 \mathrm{~mm} \mathrm{Hg}$ before the earthquake, $132.1 \pm 13.5 \mathrm{~mm} \mathrm{Hg}$ after the earthquake, $P=0.004$; 24-h diastolic blood pressure: $76.5 \pm 7.7 \mathrm{~mm} \mathrm{Hg}$ before the earthquake, $80.6 \pm 9.8 \mathrm{~mm} \mathrm{Hg}$ after the earthquake, $P=0.005)$. No increase in blood pressure was evident among patients in either the increased or reduced therapy group. Interviews with individual patients revealed that the quality of life of patients in the unchanged therapy group had declined after the earthquake in terms of housing discomfort, reduced physical activity, diet problems and work-related problems, and that it remained low.

The study by Giorgini et al. ${ }^{13}$ presents extremely important information on the state of long-term blood pressure management of earthquake victims evaluated by ambulatory blood pressure monitoring and suggests that longer-term management of blood pressure after earthquakes is required. However, the study had some limitations. It comprised only a small number of subjects, and the extensive harm suffered by those individuals after the earthquake meant that it was impossible to evaluate changes in blood pressure from the acute phase immediately after the earthquake through the subacute phase. Wide variation was also observed in the period when ambulatory blood pressure monitoring was performed $(6.9 \pm 4.5$ months before and $14.2 \pm 5.1$ months after the earthquake). Furthermore, blood pressure was evaluated at only two points-before the earthquake and $\sim 1$ year after-and questions remain as to both whether the elevation of blood pressure resulting from the earthquake was consistently prolonged until 1 year later and whether any factors other than the earthquake had an effect. Giorgini et al. ${ }^{13}$ suggested that one cause of the long-term elevation in blood pressure may have been patients' inability to receive appropriate antihypertensive therapy after the earthquake owing to missed doctor visits, loss of clinical records from earthquake damage and an insufficient supply of drugs.

Giorgini et al. ${ }^{13}$ also noted that the pronounced decline in quality of life persisted in terms of housing discomfort, reduced physical activity, diet problems and work-related problems, which suggests that chronic stress was not relieved. They consider this a possible factor in prolonging the elevation of blood pressure among victims as long as 1 year after the earthquake. As oral administration of sympatholytics was associated with the suppression of elevated blood pressure after the earthquake ${ }^{10}$ and activation of the sympathetic nervous system by psychological stress is believed to contribute significantly to the elevation of blood pressure during the acute post-earthquake phase, it is possible that subsequent activation of the reninangiotensin system may induce sodium retention and prolong the elevation of blood pressure. Additional factors such as chronic stress due to living in evacuation centers or temporary housing facilities, sleep dysfunction, reduced physical activity, increased salt intake, increased tobacco and alcohol consumption, and reduced drug adherence may further extend the period for which elevated blood pressure is maintained. Many of the victims of hurricane Katrina, which hit the southeastern United States in 2005, experienced a marked decline in blood pressure control, and it was reported that drug adherence greatly decreased as a result of inadequate social support, insufficient supplies of medication and post-traumatic stress disorder. ${ }^{14}$

The loss of clinical records may also contribute to health impairment in victims with chronic conditions. Although the Great East Japan Earthquake affected a wide area, it was the subsequent tsunami that caused the most catastrophic damage. A study of diabetes patients in a region hit especially hard by the tsunami found that clinical records, such as those containing details of drug administration, were lost, meaning that many prescriptions written before the earthquake could not be replaced and that blood pressure and glycemic control had deteriorated as long as 4 months after the earthquake. ${ }^{12}$ Clinical records from before an earthquake, particularly prescription details, are extremely important in the management of victims with chronic conditions such as hypertension and diabetes, and it may be necessary to instruct patients to use records such as medication notebooks (okusuri techou) under normal circumstances and carry them at all times should a disaster occur. It may also be necessary to construct systems that are capable of ensuring the safekeeping of clinical records even during a disaster, by means such as consolidation or cloud storage, although this may raise issues concerning potential leakage of personal information.

Although acute changes in blood pressure as a result of stress-induced activation of the sympathetic nervous system disappear over the course of a few weeks, chronic stress will not be relieved as long as patients cannot return to their pre-earthquake living, dietary and working environments; therefore, victims may remain in a long-term high-health-risk situation for $>1$ year after an earthquake. From this perspective, in the event of a major earthquake or other natural disaster, the next most important step after the initial work to secure and prepare evacuation centers and temporary housing is early recovery, that is, returning victims to living environments that are as similar to their former circumstances as possible. Medical professionals involved in the treatment of victims living in evacuation centers or temporary housing must engage in more careful, continuous management of chronic stress and blood pressure, at least until the victims can return to a semblance of their former living situations.

Natural disasters such as major earthquakes lead to a decline in blood pressure control among victims and can damage health in major ways. Many people lost family members and homes to the tsunami caused by the Great East Japan Earthquake, and the subsequent disaster at the nuclear power plant required many of the victims to be evacuated. To date-some 2 years after the disaster- $\sim 315000$ people are still living in temporary housing or other facilities, and, in addition to the primary fatalities, 2303 deaths associated with the quake have been confirmed. Delays in reconstruction are expected to further prolong the elevation of blood pressure in the victims, potentially exerting even longer-term adverse effects on victims' health. In addition to acute-phase management and the continuous management of victims' health, a rapid social response is needed at the administrative level to promote the recovery and reconstruction of the affected communities. To improve disaster medicine in the future, it will be necessary to carry out full-scale verification of the long-term state of health damage due to major earthquakes and other natural disasters, and the 'silent tsunami' of delayed social reconstruction may magnify the secondary damage to the health of disaster victims.

\section{ACKNOWLEDGEMENTS}

This work was partially supported by Banyu Life Science Foundation International. 
1 Trichopoulos D, Katsouyanni K, Zavitsanos X, Tzonou A, Dalla-Vorgia P. Psychological stress and fatal heart attack: the Athens (1981) earthquake natural experiment. Lancet 1983; 1: 441-444.

2 Leor J, Poole WK, Kloner RA. Sudden cardiac death triggered by an earthquake. N Engl J Med 1996; 334: 413-419.

3 Suzuki S, Sakamoto S, Koide M, Fujita H, Sakuramoto $\mathrm{H}$, Kuroda T, Kintaka T, Matsuo T. Hanshin-Awaji earthquake as a trigger for acute myocardial infarction. Am Heart J 1997; 134 (5 Pt 1), 974-977.

4 Kario K, Matsuo T, Kobayashi H, Yamamoto K, Shimada K. Earthquake-induced potentiation of acute risk factors in hypertensive elderly patients: possible triggering of cardiovascular events after a major earthquake. J Am Coll Cardiol 1997; 29: 926-933.

5 Kario K. Disaster hypertension: its characteristics, mechanism, and management. Circ J 2012; 76: 553-562.

6 Kario K, Ohashi T. Increased coronary heart disease mortality after the Hanshin-Awaji earthquake among the older community on Awaji Island. Tsuna Medical Association. J Am Geriatr Soc 1997; 45: 610-613.

7 Minami J, Kawano $Y$ Ishimitsu $T$, Yoshimi $H$, Takishita S. Effect of the Hanshin-Awaji earthquake on home blood pressure in patients with essential hypertension. Am J Hypertens 1997; 10: 222-225.

8 Saito K, Kim JI, Maekawa K, Ikeda Y, Yokoyama M. The great Hanshin-Awaji earthquake aggravates blood pressure control in treated hypertensive patients. $A m ~ J$ Hypertens 1997; 10: 217-221.

9 Satoh M, Kikuya M, Ohkubo T, Imai Y. Acute and subacute effects of the great East Japan earthquake on home blood pressure values. Hypertension 2011; 58 : e193-e194.

10 Tanaka K, Nakayama M, Tani Y, Watanabe K, Asai J, Hayashi Y, Asahi K, Watanabe T. The great East Japan earthquake: blood pressure control in patients with chronic kidney disease. Am J Hypertens 2012; 25 : 951-954.

11 Watanabe K, Tani Y, Tanaka K, Hayashi Y, Asahi K, Nakayama M, Watanabe T. Acute changes in home blood pressure after the Great East Japan Earthquake among patients with chronic kidney disease in Fukushima City. Clin Exp Nephrol (e-pub ahead of print 6 December 2012).

12 Ogawa S, Ishiki M, Nako K, Okamura M, Senda M, Sakamoto T, Ito S. Effects of the Great East Japan Earthquake and huge tsunami on glycaemic control and blood pressure in patients with diabetes mellitus. BMJ 2012; 2: e000830.

13 Giorgini P Striuli R, Petrarca M, Petrazzi L, Pasqualetti P, Properzi G, Desideri G, Omboni S, Parati G, Ferri C. Long-term blood pressure changes induced by the 2009 L'Aquila earthquake: assessment by $24 \mathrm{~h}$ ambulatory monitoring. Hypertens Res 2013; 36: 795-798.

14 Krousel-Wood MA, Islam T, Muntner P, Stanley E, Phillips A, Webber LS, Frohlich ED, Re RN. Medication adherence in older clinic patients with hypertension after Hurricane Katrina: implications for clinical practice and disaster management. Am J Med Sci 2008; 336: 99-104. 